\title{
Single $\mathrm{LiMn}_{2} \mathrm{O}_{4}$ Particle Lithium Ion Transfer Kinetics
}

\author{
Giorgia Zampardi, Christopher Batchelor-McAuley, Enno Kätelhön and Richard G. Compton*
}

\begin{abstract}
A stochastic investigation of lithium de-insertion from individual $\sim 200 \mathrm{~nm}$ particles of $\mathrm{LiMn}_{2} \mathrm{O}_{4}$ reveals the rate determining step at high overpotentials to be the transfer of the cation across the particle/electrolyte interface. Measurement of the (electro)chemical behaviour of the spinel is undertaken without forming a conductive composite electrode so the material is directly investigated. The kinetics of the interfacial ion transfer places a theoretical upper limit on the discharge rates of batteries using $\mathrm{LiMn}_{2} \mathrm{O}_{4}$ in an aqueous environment.
\end{abstract}

Besides the conventional employment of Li-ion batteries in the portable electronics industry, the present interest in grid power applications pushes their development towards higher rate capability, safety, thermal stability and lower $\operatorname{cost}^{[1]}$. Unlike conventional Li-ion batteries which operate in organic media, aqueous Li-ion batteries, have the advantage of being cheap, safe, and non-toxic ${ }^{[2]}$. In order to optimise the rate capability of these systems, it is of vital importance to understand the $\mathrm{Li}^{+}$ (de-)insertion reaction kinetics.

Battery materials are routinely studied using porous composite electrodes made from a mixture of the active material with polymeric binder and conductive carbon particles. However, the nature and amount, of the binder and conductive additive used strongly influences the electrochemical response of the composite ${ }^{[3]}$. In addition, the electrode porosity and thickness plays an important role in determining the electrochemical performances, this arises due to the non-homogeneous distribution of potential, current density and $\mathrm{Li}^{+}$concentration within the electrode ${ }^{[4]}$. In order to overcome this experimental limitation and facilitate the direct investigation of the behaviour of the active material, work has focused on the development of new experimental methods. To this end, Nakayama et al. employed thin $\mathrm{LiMn}_{2} \mathrm{O}_{4}$ thin film electrodes to evaluate the kinetic parameters of the interfacial $\mathrm{Li}^{+}$transfer ${ }^{[5]}$, finding the charge transfer reactions to occur faster in aqueous solutions ${ }^{[5]}$ [6]. Moreover, Kanamura et al. placing a single $\mu \mathrm{m}$-sized particle of active material in contact with a microelectrode, were able to evaluate the intrinsic cycling behaviour of $\mathrm{LiCoO}_{2}$ and $\mathrm{LiFePO}_{4}$ in organic solutions ${ }^{[7]}$.

$\mathrm{LiMn}_{2} \mathrm{O}_{4}$ has been successfully employed as a positive electrode in $\mathrm{Li}$-ion aqueous batteries since the $\mathrm{Li}^{+}$(de-)insertion occurs near the upper limit of the stability window of the electrolyte ${ }^{[2 a, 8]}$. In the present study, the intrinsic electrochemical behaviour of single $\mathrm{LiMn}_{2} \mathrm{O}_{4}$ nanoparticles $(\mathrm{d}=-200 \mathrm{~nm})$ (SI section 2) are investigated in aqueous media via the nanoimpact method. Experimentally, particles in solution are exposed to a potentiostated electrode and they may - by virtue of Brownian motion - collide with the electrochemical interface. Measurement of the resulting Faradaic current enables the rapid

[*] Dr. G. Zampardi, Dr. C. Batchelor-McAuley, Dr. E. Kätelhön, Prof. Dr. R. G. Compton, Department of Chemistry, PTCL, University of Oxford

South Parks Road, Oxford, OX1 3QZ(UK)

E-mail: Richard.compton@chem.ox.ac.uk

Supporting information for this article is given via a link at the end of the document.
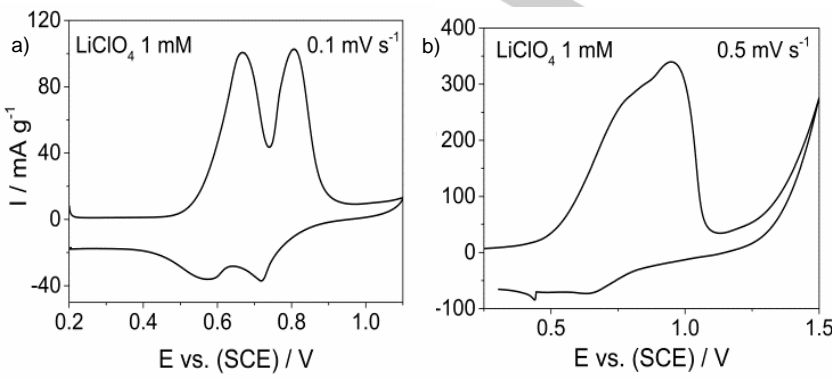

Figure 1: Cyclic voltammogram of a $\mathrm{LiMn}_{2} \overline{\mathrm{O}_{4}}$-based paste electrode in a solution containing $1 \mathrm{mM} \mathrm{LiClO}_{4}$ at a scan rate of a) 0.1 and b) $0.5 \mathrm{mV} \mathrm{s}^{-1}$. Potentials are referred to a saturated calomel reference electrode (SCE). The current is normalised per gram of active material.

and stochastic detection of large numbers of individual particles. The magnitude of the current, duration and frequency of the individual events yields direct information regarding the reactions occurring at the nanoscale ${ }^{[9]}$, in contrast with probe techniques at the micro- and nanoscale which qualitatively imaged the heterogeneities of the $\mathrm{Li}^{+}$(de-)insertion reaction in composite electrodes ${ }^{[10]}$. Moreover the nano impact method allows the investigation of active materials for Li-ion batteries whose synthesis routes do not allow the material to be simply grown on a nano electrode ${ }^{[11]}$.

First, the ensemble voltammetric response of the $\mathrm{LiMn}_{2} \mathrm{O}_{4}$ was studied by modifying a glassy carbon electrode $(r=3 \mathrm{~mm})$ with $0.4 \mathrm{mg}$ of a composite paste $\left(\mathrm{LiMn}_{2} \mathrm{O}_{4}\right.$, carbon additive and polyvinylidene fluoride binder in the weight ratio of 80:10:10). The modifying layer on the surface of the glassy carbon electrode was approximately $10 \mu \mathrm{m}$ in thickness. In agreement with the literature ${ }^{[2 a, 8 a, 12]}$, under the standard conditions of high support $\left(1 \mathrm{M} \mathrm{LiClO}_{4}\right)$ two quasi-reversible redox waves are observed at ca. +0.8 and $+0.9 \mathrm{~V}$ vs. SCE (SI figure 6 ). These peaks are ascribed as relating to the oxidation of the manganese from a mixed $3+/ 4+$ oxidation state to $4+$ and the subsequent de-insertion of the $\mathrm{Li}^{+}$from the spinel[12-13].

$$
\mathrm{LiMn}_{2} \mathrm{O}_{4}-x \mathrm{e}^{-} \rightleftarrows x \mathrm{Li}^{+}+\mathrm{Li}_{(1-x)} \mathrm{Mn}_{2} \mathrm{O}_{4}
$$

A structural cubic phase transition is reported to occur at approximately $50 \% \mathrm{Li}^{+}$de-insertion ${ }^{[12-14]}$. It is this change in structure that leads to the observation of two voltammetric redox waves. Due to agglomeration of the $\mathrm{LiMn}_{2} \mathrm{O}_{4}$ particles in solutions of high ionic strengths we use low concentrations of $\mathrm{LiClO}_{4}$. Figure 1 depicts the voltammetric response of the modified electrode in the presence of $1 \mathrm{mM} \mathrm{LiClO}_{4}$. Initially the electrode is swept anodically at a scan rate of 0.1 and $0.5 \mathrm{mV} \mathrm{s}^{-1}$. At the lower scan rate two distinct oxidative waves are observable corresponding to the de-insertion of the $\mathrm{Li}^{+}$and the corresponding structural phase change. On the reverse scan the magnitudes of the $\mathrm{Li}^{+}$insertion peaks are significantly reduced due to the low solution phase $\mathrm{Li}^{+}$concentration. At the higher scan rate of $0.5 \mathrm{mV} \mathrm{s}^{-1}$, the voltammetric $\mathrm{Li}^{+}$de-insertion wave is observed to be significantly distorted; moreover, the voltammetric oxidation peak is shifted positively by approximately $0.15 \mathrm{~V}$. The physical origin of this kinetic limitation 
likely relates to the permeation of charge through the modifying layer.

We next consider the electrochemical response of individual particles suspended in solution. A carbon fibre microdisc electrode $(r=16.5 \mu \mathrm{m})$ was submerged in a $0.65 \mathrm{pM}$ suspension of the particles (SI section 1 ) and a suitably oxidizing potential held upon the electrode. During the course of the chronoamperograms and when in the presence of the particles in solution, small bursts of current rising above the baseline were recorded. Representative examples of these recorded features, at three different potentials, are shown in Figure 2. The current features shown in Figure 2 are ascribed as relating to the stochastic arrival of the $\mathrm{LiMn}_{2} \mathrm{O}_{4}$ particles to the electrode surface and subsequently undergoing oxidative $\mathrm{Li}^{+}$de-insertion.
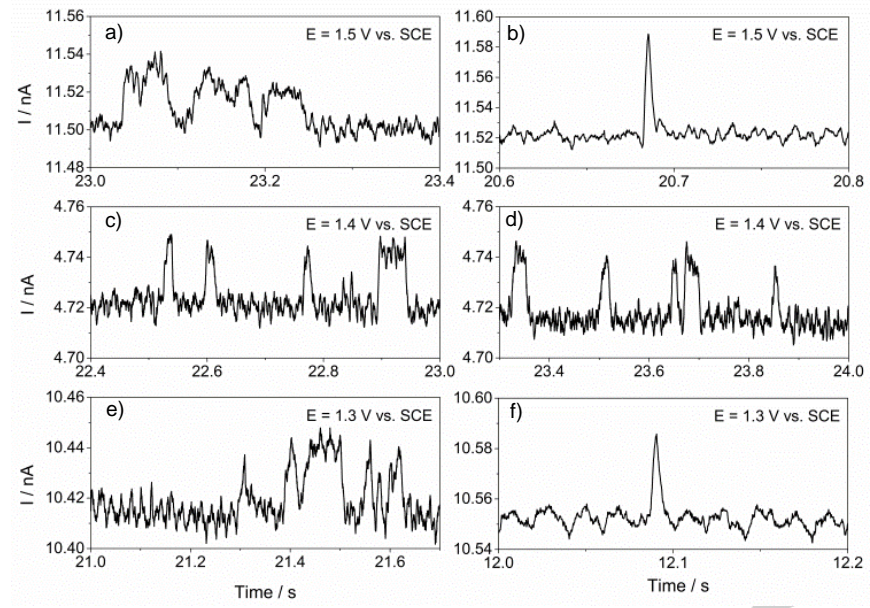

Figure 2: Chronoamperograms recorded at the carbon microdisc electrode ( $=16.5 \mu \mathrm{m}$ ) held at three different potentials (vs. SCE) $+1.5 \mathrm{~V}(\mathrm{a}, \mathrm{b}),+1.4 \mathrm{~V}$ $(\mathrm{c}, \mathrm{d})$ and $+1.3 \mathrm{~V}(\mathrm{e}, \mathrm{f})$. The solution contains $0.65 \mathrm{pM}$ of $\mathrm{LiMn}_{2} \mathrm{O}_{4}$ particles and $1 \mathrm{mM} \mathrm{LiClO}_{4}$.

The oxidative events were analysed in terms of the observed frequency of the features and the charge passed. Figure 3 presents these data as a function of the applied electrode potential. A clear threshold is observed, where at or below $+1.25 \mathrm{~V}$ (vs SCE) no oxidative features occur during the course of a scan. Also marked on Figure $3 a$ ) is the potential at which the first and second voltammetric de-insertion peaks are found (as measured from Figure 1a). An overpotential of approximate $0.6 \mathrm{~V}$ is required to drive the reaction at the individual particle scale. At least in part, this overpotential likely arises due to a contact resistance between the particle and the electrode $^{[15]}$. From Figure $3 a$ it can be seen that above a potential of $+1.275 \mathrm{~V}$ the charge of the oxidative features are found to be essentially insensitive to the electrode potential. On average $0.8 \mathrm{pC}$ of charge is passed during the course of a collision event. From the experimentally determined average particle dimensions $(\mathrm{d}=200 \mathrm{~nm})$ and assuming complete deinsertion of the lithium from the spinel, then the predicted average charge per collision event is found to be ca. 9 pC. Hence, it is concluded that during the course of an oxidative event on average $\sim 10 \%$ of the $\mathrm{Li}^{+}$is de-inserted from the particles.

Figure $3 b$ represents the average frequency of the oxidative events. Again above the threshold of $+1.25 \mathrm{~V}$ and
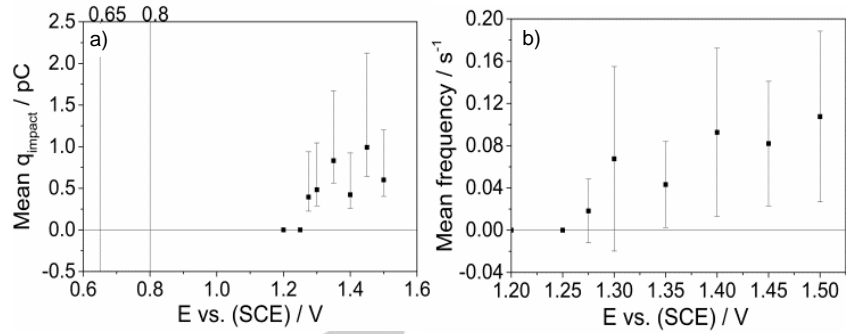

Figure 3: a) Mean charge obtained from the $\mathrm{LiMn}_{2} \mathrm{O}_{4}$ particle impacts (errors represent the interquartile range), also shown for comparison are the experimentally recorded ensemble potentials for the lithium de-insertion process. b) mean impacts frequency per chronoamperogram (25 s) as a function of the potential applied at the carbon microdisc electrode in a solution containing $1 \mathrm{mM} \mathrm{LiClO}_{4}$.

within the error of the measurement the impact frequency is found to be near constant. Using the given average particle radius and the Stokes-Einstein equation then the average particle diffusion coefficient is predicted to be $1.6 \times 10^{-12} \mathrm{~m}^{2} \mathrm{~s}^{-1}$. From this diffusion coefficient and using an integrated form of the Shoup-Szabo equation it is possible to roughly estimate the expected impact frequency to be $0.15 \mathrm{~s}^{-1}$. As can be seen from Figure $3 b$ the experimentally reported frequency is fully consistent with this calculated value, where the estimated frequency is based upon a diffusion only mass-transport model, assumes exhaustive oxidation, whilst neglects hindered diffusion $[16]$

At potentials above $+1.275 \mathrm{~V}$ vs. SCE, the average duration of the oxidative features are found to be $54 \pm 23 \mathrm{~ms}$ (see SI figure 7). This period of time is significantly greater than the duration of the impulse response of the filter used during the course of the measurements $(100 \mathrm{~Hz}$ passive RC filter with a falltime [90-10\%] of approximately $3.5 \mathrm{~ms})^{[17]}[18]$. Consequently, for many of the recorded oxidative features the current yields a direct measure of the $\mathrm{Li}^{+}$de-insertion rate occurring at an individual particle. For the majority of the events, the duration of the features is clearly defined i.e. they exhibit sharp transitions at the onset and end of the redox event. Given that each feature corresponds to only a partial oxidation of the particles, it is concluded that the duration of the events directly reflects the residence time of the particle at the electrochemical interface. Importantly, for events of longer durations the current is found to be essentially constant over the course of a single event.

The magnitude of the average current measured ( $14 \mathrm{pA})$ over the course of the oxidative events is essentially invariant above $+1.3 \mathrm{~V}$ vs. SCE with the applied potential (SI figure 8). At this rate of oxidation/de-insertion it would take approximately 0.5 $\mathrm{s}$ to remove $50 \%$ of the lithium from a particle. This is a comparatively high rate of de-insertion. In comparison the voltammetric oxidation of the ensemble occurs over the course of ca. 4000 seconds (at $0.1 \mathrm{mV} \mathrm{s}^{-1}$ ). The invariance of the current during the course of an individual collision event and its insensitivity to the applied potential strongly implies that the measured rate of $\mathrm{Li}^{+}$de-insertion represents an upper limit for which the initial $10 \%$ of lithium may be removed from the particle.

Upon collision of a single nanoparticle with a potentiostated electrochemical interface, one may consider four fundamental steps that might determine the rate of oxidation (i.e. $\mathrm{Li}^{+}$de-insertion): i) oxidative removal of electrons from the 
particle, ii) mass-transport of the $\mathrm{Li}^{+}$ions in the particle to the solid/solution interface, iii) transfer of the $\mathrm{Li}^{+}$ion across the interface and iv) mass-transport in the solution phase of the ions away from the particle. First, if i) was the rate determining step, then in accordance with the Butler-Volmer equation, the resulting current would be expected to scale essentially exponentially with the applied potential. As shown in the SI Figure 8, this is not found to be the case. Second, step iv) being the rate determining step can be excluded on the basis of the known aqueous diffusion coefficient of lithium ions $\left(\mathrm{D}_{\mathrm{Li}}{ }^{+}=\right.$ $\left.1.029 \times 10^{-5} \mathrm{~cm}^{2} \mathrm{~s}^{-1}\right)^{[19]}[20]$. Third, the diffusion coefficient of the lithium ions within the crystal structure is significantly lower and likely takes a value between $10^{-10}-10^{-13} \mathrm{~cm}^{2} \mathrm{~s}^{-1}[13]$; however, due to the geometry of the system the current would not be anticipated to exhibit a steady-state flux, hence step ii) being rate determining is not consistent with the experimental observations (see SI section 5.1 for more information). Finally, of the above proposed steps only the transfer of ions across the solid/solution interface yields a rate of oxidation that likely to exhibit a steady-state (SI section 5.2). Hence, from the reported mean steady-state current per particle and the particles average geometric surface area the rate of lithium interfacial transfer across the particle/electrolyte interface is determined to be $\sim 0.1$ $\mathrm{mol} \mathrm{m} \mathrm{m}^{-2} \mathrm{~s}^{-1}$.

In conclusion, the nano-impact method was applied to the study of the $\mathrm{Li}^{+}$de-insertion kinetics from single $\mathrm{LiMn}_{2} \mathrm{O}_{4}$ particles in an aqueous environment. This general methodology provides an alternate and complementary route to the investigation of the electrochemical behaviour of active materials without the influence or presence of binder and conductive carbon additives. Furthermore, this work has demonstrated that at high overpotentials the intrinsic rate determining step of the $\mathrm{Li}^{+}$(de-)insertion process from $\mathrm{LiMn}_{2} \mathrm{O}_{4}$ is the transfer of ions across the particle/electrolyte interface.

\section{Acknowledgements}

Mr. S. V. Sokolov is thanked for the zeta potential and the NTA measurements. The research leading to these results has received funding from the European Research Council under the European Union's Seventh Framework Program (FP/20072013)/ERC Grant Agreement No. 320403.

Keywords: Lithium (de-)insertion • Lithium-ion aqueous batteries $\cdot$ Lithium manganese oxide $\bullet$ Nanoimpact $\bullet$ Single nanoparticle

\section{References}

[1] Z. G. Yang, J. L. Zhang, M. C. W. Kintner-Meyer, X. C. Lu, D. W. Choi, J. P. Lemmon, J. Liu, Chem. Rev. 2011, 111, 35773613.

[2] aW. Li, J. R. Dahn, D. S. Wainwright, Science 1994, 264, 11151118; bJ. Stojadinovic, A. Dushina, R. Trocoli, F. La Mantia, Chem.Plus Chem. 2014, 79, 1507-1511.
[3] aF. La Mantia, R. A. Huggins, Y. Cui, J. Appl. Electrochem. 2013, 43, 1-7; bR. Dominko, M. Gaberscek, J. Drofenik, M. Bele, J. Jamnik, Electrochim. Acta 2003, 48, 3709-3716.

[4] J. T.-A. Newman, K. E., Electrochemical Systems, 3rd Edition ed., Wiley, 2004.

[5] N. Nakayama, T. Nozawa, Y. Iriyama, T. Abe, Z. Ogumi, K. Kikuchi, J. Power Sources 2007, 174, 695-700.

[6] T. Abe, F. Sagane, M. Ohtsuka, Y. Iriyama, Z. Ogumi, J. Electrochem. Soc. 2005, 152, A2151-A2154.

[7] aK. Dokko, N. Nakata, K. Kanamura, J. Power Sources 2009, 189, 783-785; bH. Munakata, B. Takemura, T. Saito, K. Kanamura, J. Power Sources 2012, 217, 444-448.

[8] aW. Li, W. R. McKinnon, J. R. Dahn, J. Electrochem. Soc. 1994 141, 2310-2316; bA. Chaturvedi, V. Aravindan, P. Hu, R. R. Prabhakar, L. H. Wong, C. Kloc, S. Madhavi, Appl. Mater. Today 2016, 5, 68-72.

[9] aE. Katelhon, A. Feng, W. Cheng, S. Eloul, C. BatchelorMcAuley, R. G. Compton, J. Phys. Chem. C 2016, 120, 1702917034; bC. S. Lim, S. M. Tan, Z. Sofer, M. Pumera, ACS Nano 2015, 9, 8474-8483.

[10] aY. Takahashi, A. Kumatani, H. Munakata, H. Inomata, K. Ito, K. Ino, H. Shiku, P. R. Unwin, Y. E. Korchev, K. Kanamura, T. Matsue, Nat. Commun. 2014, 5, 7; bG. Zampardi, E. Ventosa, F La Mantia, W. Schuhmann, Chem. Commun. 2013, 49, 93479349; cG. Zampardi, E. Ventosa, F. La Mantia, W. Schuhmann, Electroanal. 2015, 27, 1017-1025.

[11] J. Clausmeyer, J. Masa, E. Ventosa, D. Ohl, W. Schuhmann, Chem. Commun. 2016, 52, 2408-2411.

[12] D. Guyomard, J. M. Tarascon, J. Electrochem. Soc. 1993, 140, 3071-3081.

[13] D. Aurbach, M. D. Levi, E. Levi, H. Teller, B. Markovsky, G. Salitra, U. Heider, L. Heider, J. Electrochem. Soc. 1998, 145, 3024-3034.

[14] M. Bianchini, F. Fauth, E. Suard, J. B. Leriche, C. Masquelier, L. Croguennec, Acta Crystallogr. B 2015, 71, 688-701.

[15] H. Hodson, X. T. Li, C. Batchelor-McAuley, L. D. Shao, R. G. Compton, J. Phys. Chem. C 2016, 120, 6281-6286.

[16] aS. Eloul, E. Katelhon, C. Batchelor-McAuley, K. Tschulik, R. G. Compton, J. Electroanal. Chem. 2015, 755, 136-142; bS. Eloul, R. G. Compton, J. Phys. Chem. Lett. 2016, 7, 4317-4321; cS. Eloul, E. Kätelhön, R. G. Compton, Phys. Chem. Chem. Phys. 2016, 18, 26539.

[17] C. Batchelor-McAuley, J. Ellison, K. Tschulik, P. L. Hurst, R. Boldt, R. G. Compton, Analyst 2015, 140, 5048-5054.

[18] E. Katelhon, E. E. L. Tanner, C. Batchelor-McAuley, R. G. Compton, Electrochim. Acta 2016, 199, 297-304.

[19] CRC Handbook of Chemistry and Physics, Internet Version, 85th Edition ed., CRC Press, Boca Raton, FL, 2005.

[20] Taking a hypothetical surface concentration of $1 \mathrm{M} \mathrm{Li}$ ions, the mass-transport limited oxidation rate is predicted to be $125 \mathrm{nA}$. 
Exploring the intrinsic response of the active materials used in Li-ion batteries is challenging when conventional composite electrodes made with binder and conductive additive are used. Here, the nanoimpact method applied to individual $\mathrm{LiMn}_{2} \mathrm{O}_{4}$ nanoparticles gives insight into the intrinsic $\mathrm{Li}^{+}$(de)-insertion process.

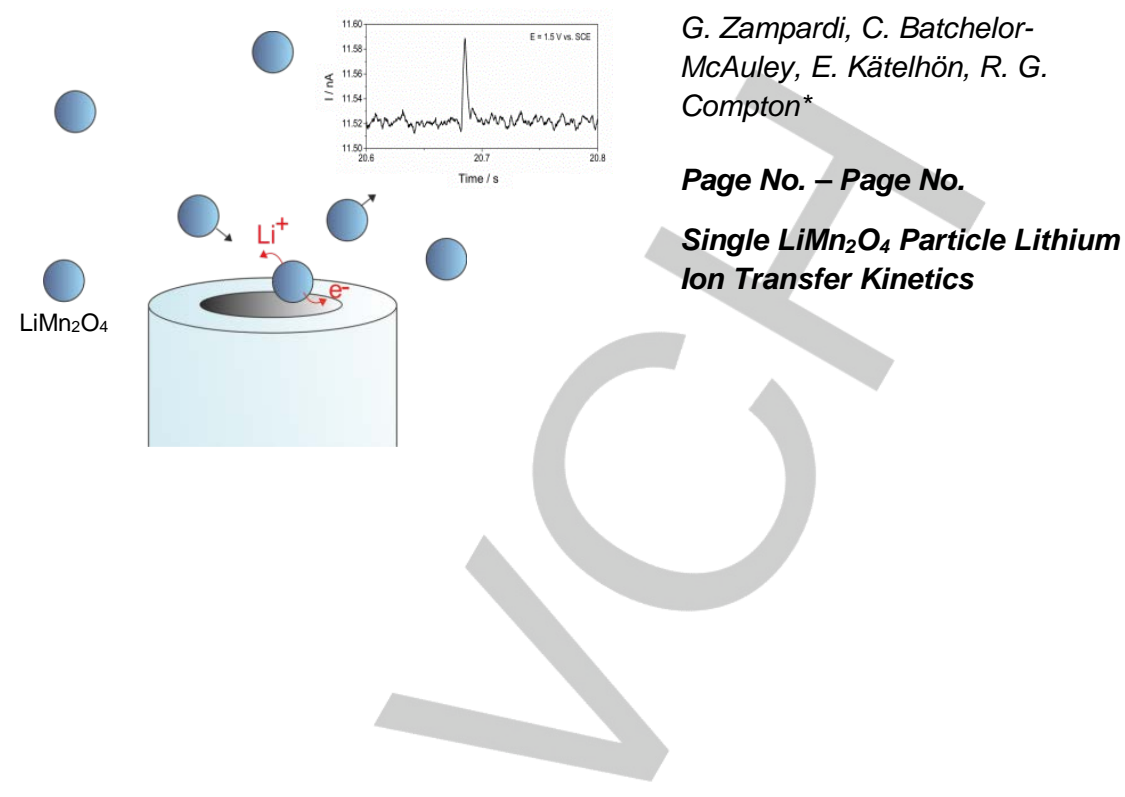

